\title{
Erratum to: Effect of Lithium Tetrafluoroborate on the Solubility of Carbon Dioxide in the Ionic Liquid 1-Butyl-3-Methylimidazolium Tetrafluoroborate
}

\author{
Sara Durano Arnó • Susana Lucas • Alireza Shariati • Cor J. Peters
}

Published online: 6 March 2013

(C) Springer Science+Business Media New York 2013

\section{Erratum to: J Solution Chem (2012) 41:2173-2185 DOI 10.1007/s10953-012-9927-z}

The correct affiliation of Prof. Cor J. Peters at Eindhoven University of Technology is as follows:

Department of Chemical Engineering and Chemistry, Separations Technology Group, Eindhoven University of Technology, P. O. Box 513, $5600 \mathrm{MB}$ Eindhoven, The Netherlands.

The online version of the original article can be found under doi:10.1007/s10953-012-9927-z.

S. D. Arnó · C. J. Peters $(\bowtie)$

Department of Process Energy, Faculty of Mechanical, Maritime, and Materials Engineering, Delft University of Technology, Leegwaterstraat 44, 2628 CA Delft, The Netherlands

e-mail: c.j.peters@tudelft.nl

S. Lucas

Chemical Engineering and Environmental Technology Department, University of Valladolid, C/Prado de la Magdalena s/n, 47011 Valladolid, Spain

A. Shariati

Natural Gas Engineering Department, School of Chemical and Petroleum Engineering, Shiraz University, 71345 Shiraz, Iran

e-mail: shariati@shirazu.ac.ir

C. J. Peters

Chemical Engineering Department, The Petroleum Institute, P. O. Box 2533, Abu Dhabi, United Arab Emirates

C. J. Peters

Department of Chemical Engineering and Chemistry, Separations Technology Group, Eindhoven University of Technology, P. O. Box 513, 5600 MB Eindhoven, The Netherlands 